Corresponding author: linashao@med.umich.edu

(c) 2020 Lee et al. This article is distributed under the terms of the Creative Commons Attribution-NonCommercial License, which permits reuse and redistribution, except for commercial purposes, provided that the original author and source are credited.

Ontology terms: chronic myelogenous leukemia; eosinophilia; Ph-positive acute lymphoblastic leukemia; pre-Bcell acute lymphoblastic leukemia

Published by Cold Spring Harbor Laboratory Press

doi:10.1101/mcs.a004937

\section{The diagnostic challenges and clinical course of a myeloid/lymphoid neoplasm with eosinophilia and ZBTB20-JAK2 gene fusion presenting as B-lymphoblastic leukemia}

\author{
Winston Y. Lee, ${ }^{1}$ Ruthann B. Pfau, ${ }^{2}$ Sarah M. Choi, ${ }^{1}$ Jiong Yang, ${ }^{1}$ Hong Xiao, ${ }^{1}$ \\ Eileen M. Putnam, ${ }^{1}$ Russell JH. Ryan, ${ }^{1}$ Dale L. Bixby, ${ }^{3}$ and Lina Shao ${ }^{1}$ \\ ${ }^{1}$ Department of Pathology, Michigan Medicine, University of Michigan, Ann Arbor, Michigan 48109-2800, \\ USA; ${ }^{2}$ Institute of Genomic Medicine, Nationwide Children's Hospital and Department of Pathology, the Ohio \\ State University, Columbus, Ohio 43205-2664, USA; ${ }^{3}$ Division of Hematology and Medical Oncology, \\ Department of Internal Medicine, Michigan Medicine, University of Michigan, Ann Arbor, Michigan \\ 48109-2800, USA
}

Abstract We report the diagnostic challenges and the clinical course of a patient with an extraordinary presentation of B-lymphoblastic leukemia (B-ALL) with eosinophilia. We identified a novel ZBTB20-JAK2 gene fusion as a chimeric RNA transcript using the Archer platform. This gene fusion from the same patient was recently identified by Peterson et al. (2019) at the genomic level using a different sequencing technology platform. The configuration of this gene fusion predicts the production of a kinase-activating JAK2 fusion protein, which would normally lead to a diagnosis of Philadelphia chromosome-like B-ALL (Ph-like B$A L L)$. However, the unusual presentation of eosinophilia led us to demonstrate the presence of this gene fusion in nonlymphoid hematopoietic cells by fluorescence in situ hybridization (FISH) studies with morphologic correlation. Therefore, we believe this disease, in fact, represents blast crisis arising from an underlying myeloid neoplasm with JAK2 rearrangements. This case illustrates the difficulty in differentiating Ph-like B-ALL and myeloid/lymphoid neoplasm with eosinophilia and gene rearrangements (MLN-EGR) in blast crisis. As currently defined, the diagnosis of MLN-EGR relies on the hematologic presentations and the identification of marker gene fusions (including PCM1-JAK2, ETV6-JAK2, and BCR-JAK2). However, these same gene fusions, when limited to B-lymphoblasts, also define Ph-like BALL. Yet, our case does not conform to either condition. Therefore, the assessment for lineage restriction of gene rearrangements to reflect the pathophysiologic difference between B-ALL and MLN-EGR in blast crisis is likely a more robust diagnostic approach and allows the inclusion of MLN-EGR with novel gene fusions.

[Supplemental material is available for this article.]

\section{INTRODUCTION}

Kinase-activating JAK2 fusion proteins derived from gene rearrangements are increasingly recognized in hematopoietic neoplasms. These chimeric proteins, composed of a JAK2 kinase domain and the dimerization domain of a fusion partner, are the hallmarks of a subset of Philadelphia chromosome-like B-precursor acute lymphoblastic lymphoma/leukemia 
COLD SPRING HARBOR Molecular Case Studies
ZBTB20-JAK2 gene fusion in myeloid/lymphoid neoplasm with eosinophilia presenting as B-ALL

(Ph-like B-ALL) and myeloid/lymphoid neoplasms with PCM1-JAK2 (MLN-PJ) (Reiter et al. 2005; Adélaïde et al. 2006; Ehrentraut et al. 2013; Patterer et al. 2013; Bain and Ahmad 2014; Roberts et al. 2014, 2017). Ph-like B-ALLs lack BCR-ABL1 fusion but share a similar gene expression profile and unfavorable clinical behavior to BCR-ABL1-positive B-ALL (Roberts et al. 2014, 2017). Although only 7\% of Ph-like B-ALLs harbor JAK2 rearrangements, at least 19 fusion partners have been described. Some of the fusions, including PCM1-JAK2 and variants, are also present in MLN-PJ (Tasian et al. 2017). MLN-PJ, a provisional entity under the broader category of myeloid/lymphoid neoplasm with eosinophilia and gene rearrangements (MLN-EGR), was established using PCM1-JAK2 as the index genetic abnormality and recently expanded to include ETV6-JAK2 and BCR-JAK2 as variants (Bain and Ahmad 2014; Swerdlow et al. 2017). The hematologic presentations, often with eosinophilia and features of myeloproliferative, myelodysplastic, or overlapping neoplasms, are distinct from B-ALLs. However, transformed B-ALL in MLN-PJ can occur (Reiter et al. 2005; Bain and Ahmad 2014; Tang et al. 2018). Therefore, separating these two entities can be difficult, especially in cases without a history of myeloid neoplasm. This report highlights an extraordinary case of a B-ALL with eosinophilia that harbors a novel JAK2 fusion and may have arisen from an underlying myeloid neoplasm.

\section{RESULTS}

\section{Clinical Presentation}

The patient is a 33-yr-old woman who was referred to our institution with complaints of malaise, dyspnea, and fatigue for $3 \mathrm{wk}$. Initial laboratory studies revealed a leukocytosis $(\mathrm{WBC}=42.9 \mathrm{~K} / \mu \mathrm{L})$ with $45 \%$ circulating blasts and absolute eosinophilia $(2.6 \mathrm{~K} / \mu \mathrm{L})$, anemia (hemoglobin $=6.2 \mathrm{~g} / \mathrm{dL}$ ), and thrombocytopenia (platelets $=12 \mathrm{~K} / \mu \mathrm{L}$ ) (Fig. 1A). A computed tomography scan revealed nonspecific diffuse lymphadenopathy and mild splenomegaly. A bone marrow aspirate and biopsy demonstrated increased blasts (60.4\%) and increased eosinophil fraction (16\%) (Fig. 1B,C). Flow cytometry analysis detected increased abnormal B-lymphoblasts, positive for CD19, CD20 (partial), CD10, TdT, and CD34, consistent with a pre-B-ALL.

\section{Genomic Analysis}

The presentation of B-ALL with eosinophilia elicits a differential diagnosis that includes B-ALL (including subsets with interleukin-3 gene fusions [Meeker et al. 1990]) and MLNEGR in blast crisis. A JAK2 rearrangement (JAK2-R) was detected as a balanced translocation between Chromosomes 3q13 and 9p24 by karyotype analysis (Fig. 2A) and confirmed with a fluorescence in situ hybridization (FISH) study using JAK2 break-apart probes. Cells with bean-shaped/bilobed nuclei (likely maturing myeloid elements) are positive for $J A K 2-R$ (72\% of 53 nuclei) (Fig. 2B). The cell fractions with JAK2-R were higher than the blast fractions at diagnosis (80\% JAK2-R nuclei vs. $41 \%$ blasts by marrow aspirate smear differential) and after the first induction (21.5\% JAK2-R nuclei vs. 2.6\% blasts by marrow aspirate smear differential or $6 \%$ blasts of viable cells by MRD-flow cytometry). Following reinduction, the blast fraction $(0.4 \%$ by aspirate smear differential) decreased further, but the JAK2-R was not detected by FISH studies despite persistent minimal residual disease (MRD) $(0.19 \%$ of viable cells by MRD flow cytometry). This discordance in neoplastic cell fractions and the presentation of eosinophilia led us to confirm the presence of JAK2-R in erythroid precursors using FISH assay with morphologic correlation, performed on destained Wright-Giemsa-stained marrow aspirate smears (Fig. 2C). Break-apart signals in myeloid elements, although present, were obscured by autofluorescent granules precluding 

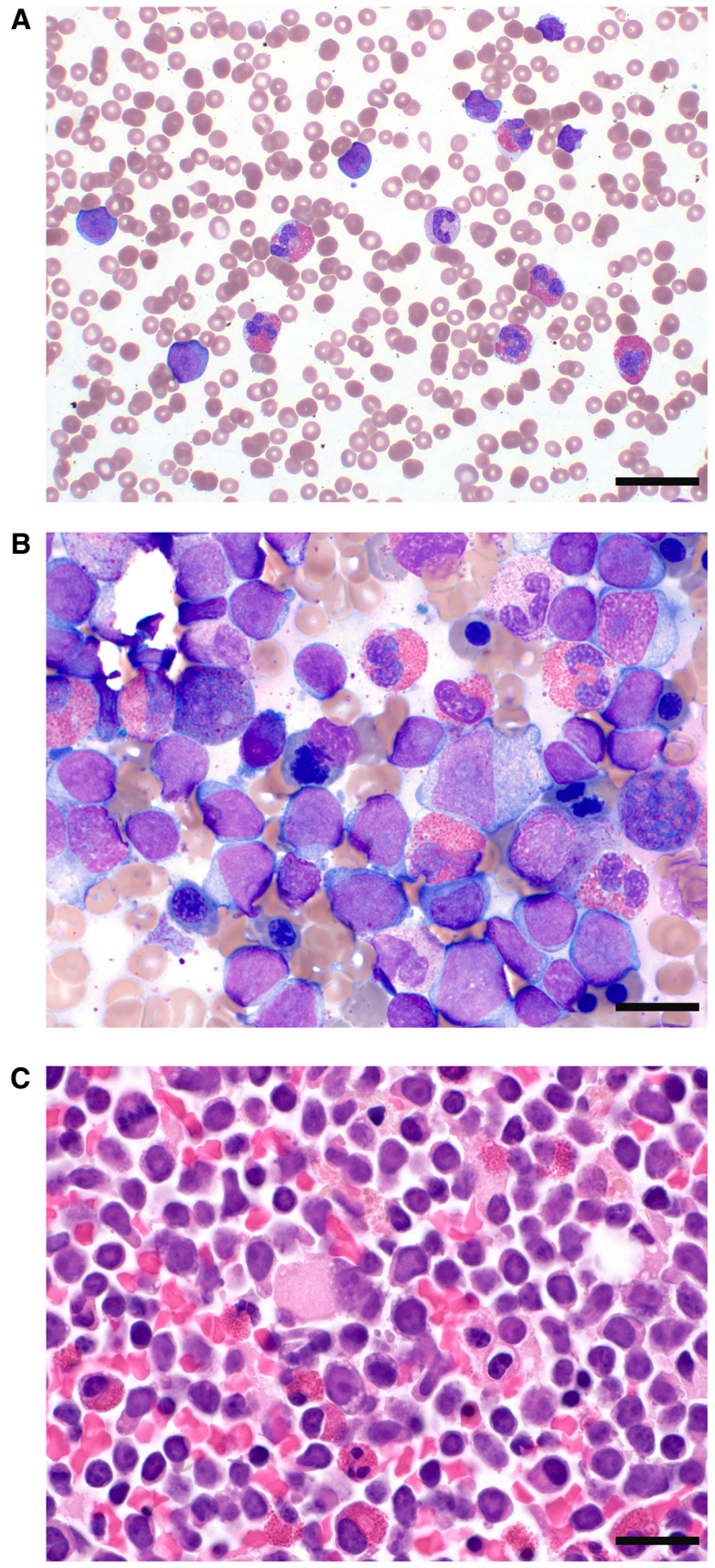

Figure 1. B-lymphoblastic leukemia/lymphoma and absolute eosinophilia. (A) A Wright-Giemsa-stained peripheral blood smear demonstrates increased circulating blasts and increased mature eosinophils (original magnification, 500x). Increased blasts and immature eosinophils in bone marrow are seen on the WrightGiemsa-stained bone marrow aspirate smear (B) (original magnification, 10000x) and in the hematoxylin and eosin-stained section of the bone marrow core biopsy $(C)$ (original magnification, 1000x). Scale bars, (A) $20 \mu \mathrm{m} ;(B, C) 10 \mu \mathrm{m}$.

quantification (Fig. 2C). The detection of JAK2-R in multiple hematopoietic lineages indicates a defect at the level of pluripotent hematopoietic stem cells (HSCs), consistent with an underlying MLN-EGR. 
$8 \mathrm{CSH} \&$ C O L D S P R IN G H A R B O R Molecular Case Studies
ZBTB20-JAK2 gene fusion in myeloid/lymphoid neoplasm with eosinophilia presenting as B-ALL

A

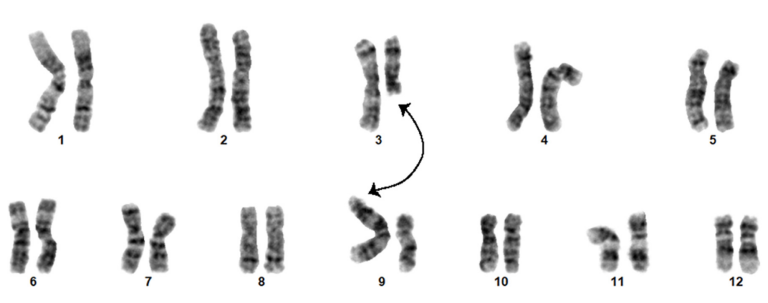

II 4 a

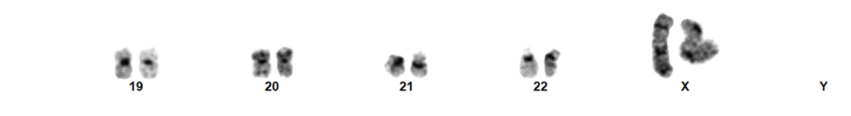

B

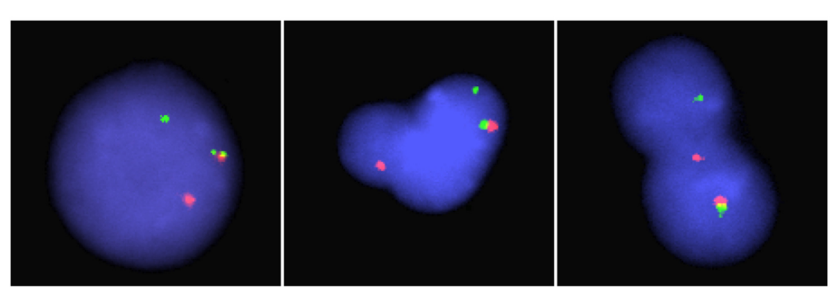

C

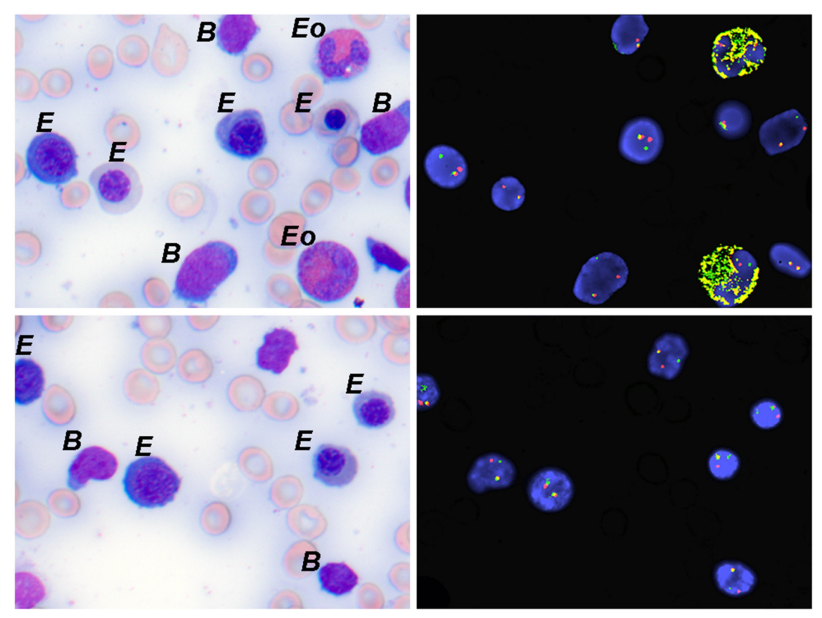

D

Chr 3:114069121 Chr 9:5081725 (hg19)

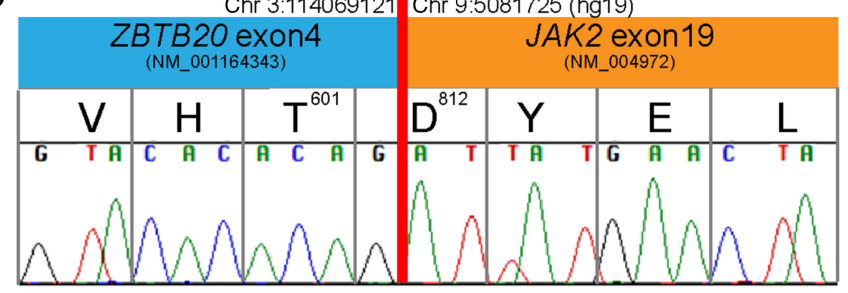

E



Figure 2. See legend on following page. 
COLD SPRING HARBOR Molecular Case Studies
ZBTB20-JAK2 gene fusion in myeloid/lymphoid neoplasm with eosinophilia presenting as B-ALL

An in-frame fusion between ZBTB20 exon 4 as the $5^{\prime}$ partner (ZBTB20:NM_00116342 [exon:4] Chr 3:114069121) and JAK2 exon19 as the $3^{\prime}$ partner (JAK2:NM_004972 [exon:19] Chr 9:5081725) was identified using the Archer next-generation sequencing (NGS) assay and analysis based on human genome assembly version hg19 (see Table 1) . ZBTB20 is reportedly expressed in germinal center B cells, plasma cells, and neuronal tissues, but the expression in myeloid/erythroid precursors remains unknown (Chevrier et al. 2014; Wang and Bhattacharya 2014; Maeda 2016; Zhu et al. 2018). Expression of ZBTB20-JAK2 RNA chimeric transcripts was confirmed by Sanger sequencing on CDNA amplicons (Fig. 2D). The predicted chimeric protein contains one dimerizing BTB/POZ domain and one zinc-finger-C2H2 domain of ZBTB2O at the amino terminus fused with the JAK2-tyrosine-kinase domain (Fig. 2E), allowing for constitutive activation of ZBTB20-JAK2 fusion protein through partner-mediated oligomerization, similar to other known kinase-activating JAK2 gene fusions (Roberts et al. 2014; Maeda 2016; Zhu et al. 2018). Furthermore, the cytogenomic array identified a deep 107-kB deletion at Chromosome 7p12, consistent with a homozygous IKZF1 deletion (data not shown). IKZF1 deletion is a frequent genetic event in Ph-like B-ALL but has also been reported in B-ALL transformed from myeloproliferative neoplasms (Mullighan et al. 2008; van der Veer et al. 2013; Tasian et al. 2017). These findings are consistent with B-ALL arising from an underlying myeloid neoplasm.

\section{Treatment Course}

The patient was initiated with induction chemotherapy with CALGB 8811 plus rituximab (R-Larson protocol). Notably, the patient's eosinophil count continued to rise rapidly (it peaked at $8 \mathrm{~K} / \mu \mathrm{L}$ ), but dropped precipitously along with the blast count after initiation of chemotherapy. A bone marrow aspirate and biopsy at day 30 with normalization of blood cell counts was morphologically negative but positive for MRD ( $6 \%$ of viable cells and $8.5 \%$ of mononuclear cells by flow cytometry). Following reinduction with the B-arm of hyperCVAD, she continued to be in a morphologic remission, but MRD persisted $(0.19 \%$ of viable cells and $3.1 \%$ of mononuclear cells by flow cytometry). Given her persistent MRD level of disease, one cycle of blinatumomab was given, and she then underwent an 8/8 matched unrelated donor transplant. A bone marrow aspiration and biopsy performed on post-transplant day 104 demonstrated a morphologic remission with no evidence of minimal residual disease by flow cytometry. The patient remains in remission now at $200 \mathrm{~d}$ post-transplant.

Figure 2. Identification and characterization of a novel ZBTB20-JAK2 gene rearrangement. (A) A balanced $\mathrm{t}(3 ; 9)(q 13 ; p 24)$, as indicated by the arrows, is detected by conventional G-banding karyotype analysis. (B) JAK2 gene rearrangement is confirmed by using a break-apart FISH probe set in interphase nuclei (original magnification, 1000×). The red signals are 5' JAK2 probes and the green signals are 3' JAK2 probes. The yellow signals and the red and green signals in close tandem represent overlapping red and green signals, consistent with intact JAK2 loci. Positive break-apart signals, consistent with JAK2 rearrangements, are present in cells with bean-shaped nuclei and bilobed nuclei, possibly representing immature and mature eosinophils. (C) JAK2 rearrangements in erythroid elements (E) and blasts (B) are confirmed by comparing a Wright-Giemsa-stained bone marrow aspirate smear (original magnification, 400×, with digital magnification, $2.5 \times$ ) and the JAK2 break-apart FISH assay (original magnification, 1000x) performed after destaining. Although break-apart signals can be seen in maturing eosinophils (Eo), autofluorescence of cytoplasmic granules preclude definitive assessment. (D) A modified DNA chromatogram derived from Sanger sequencing summarizes the breakpoints in ZBTB2O and JAK2 genes (genomic coordinates provided on top), the site of fusion (red line), the resultant DNA sequence, and the corresponding amino acid (with the amino acid residue positions of each protein partner listed as superscripts). ( $E$ ) The resultant fusion protein is predicted to contain the BTB/POZ (dimerization) domain and a zf-C2H2 domain from ZBTB2O and the protein tyrosine kinase domain from JAK2. 


\begin{tabular}{|c|c|c|c|c|c|c|c|c|c|c|c|}
\hline Gene & $\begin{array}{l}\text { Chro- } \\
\text { mo- } \\
\text { some }\end{array}$ & $\begin{array}{l}\text { HGVS } \\
\text { DNA } \\
\text { refer- } \\
\text { ence }\end{array}$ & $\begin{array}{l}\text { HGVS } \\
\text { protein } \\
\text { refer- } \\
\text { ence }\end{array}$ & $\begin{array}{l}\text { Variant } \\
\text { type }\end{array}$ & $\begin{array}{c}\text { Predicted } \\
\text { effect } \\
\text { (substitution, } \\
\text { deletion, etc.) }\end{array}$ & $\begin{array}{c}\text { dbSNP/ } \\
\text { dbVar } \\
\text { ID }\end{array}$ & $\begin{array}{c}\text { Genotype } \\
\text { (hetero- } \\
\text { zygous/ } \\
\text { homo- } \\
\text { zygous) }\end{array}$ & $\begin{array}{l}\text { ClinVar ID } \\
\text { (optional) }\end{array}$ & $\begin{array}{l}\text { Parent of } \\
\text { origin } \\
\text { (optional) }\end{array}$ & $\begin{array}{l}\text { Observed effect } \\
\text { (if shown to be } \\
\text { different from } \\
\text { predicted effect) } \\
\text { (optional) }\end{array}$ & $\begin{array}{c}\text { Comments } \\
\text { (optional) }\end{array}$ \\
\hline ZBTB2O & 3 & $\begin{array}{c}\text { Chr 3: } \\
114069121\end{array}$ & & Fusion & $\begin{array}{c}\text { NM_00116342: } \\
\text { c.1_1804:: }\end{array}$ & $\mathrm{n} / \mathrm{a}$ & $\mathrm{n} / \mathrm{a}$ & SCV001190540 & $\mathrm{n} / \mathrm{a}$ & & Somatic \\
\hline JAK2 & 9 & $\begin{array}{l}\text { Chr 9: } \\
5081725\end{array}$ & & & $\begin{array}{l}\text { NM_004972: } \\
\text { c.2324_* } \\
\text { (p.T601:: } \\
\text { p.D812) }\end{array}$ & & & & & & \\
\hline
\end{tabular}

\section{DISCUSSION}

This case illustrates the difficulty in differentiating Ph-like B-ALL and MLN-EGR in blast crisis. The key distinction is the ability of the gene fusions to drive neoplastic HSCs in MLN-EGR, sustaining multilineage hematopoietic differentiation, whereas the effect in Ph-B-ALL is restricted to the lymphoid lineage. Per the current World Health Organization (WHO) classification, the diagnosis of MLN-EGR relies on the hematologic presentations and the identification of "known" gene fusions, many of which are shared with Ph-like B-ALL. Our case does not conform to either condition. Eosinophilia, although helpful in this case, is not universally present in MLN-EGR. Two cases of B-ALLs without eosinophilia were retrospectively found to harbor PCM1-JAK2 in multiple lineages using FISH studies with morphologic correlation, consistent with MLN-PJ in blast crisis (Tang et al. 2018). Therefore, assessment for lineage restriction of gene rearrangements to reflect the pathophysiologic difference between B-ALL and MLN-EGR in blast crisis is likely a more robust diagnostic approach and allows the inclusion of MLN-EGR with novel gene fusions. FISH study with morphologic correlation represents a tractable way to routinely assess lineage restriction of gene rearrangements.

Although it is not known whether eosinophilia was present in this patient prior to the presentation of B-ALL, a subclinical myeloid neoplasm with JAK2 rearrangement likely preceded the onset of B-ALL in our patient. In MLN-PJ that manifests as chronic eosinophilic leukemia, remission following treatment with JAK2 inhibitors has been reported (Bain and Ahmad 2014; Schwaab et al. 2015; Lierman et al. 2012; Rumi et al. 2015, 2013; Reiter et al. 2005). It is tantalizing to speculate whether the blast crisis was preceded by a subclinical prodromal state that may serve as a window of opportunity for JAK inhibitor treatment. However, because of its rarity, there is a lack of knowledge about robust clinical features of the prodromal state. Therefore, only by consistently making a diagnostic distinction between Ph-like B-ALL and B-ALL arising from MLN-EGR can we accumulate evidence and experience with this unique disease.

A different group has reported the detection of ZBTB20-JAK2 fusion from the same patient using mate-pair sequencing (Peterson et al. 2019). Their report offers a different level of information and nicely complements our findings. They identified the breakpoints and the site of fusion to be within intron 4 of ZBTB2O and intron 18 of JAK2 at the genomic level and deduced a productive rearrangement based on the genomic configuration. In their report, they speculated on the possibility of MLN-EGR but did not offer additional evidence. Furthermore, their reports focused on the initial presentation without providing a detailed clinical course. In contrast, our approach using the Archer platform characterizes the chimeric RNA transcript by sequencing the complementary DNA, providing evidence for active transcription of the gene fusion. Importantly, we demonstrated JAK2-R in nonlymphoid lineage 
COLD SPRING HARBOR Molecular Case Studies
ZBTB20-JAK2 gene fusion in myeloid/lymphoid neoplasm with eosinophilia presenting as B-ALL

cells, supporting the possibility of underlying MLN-EGR, and presented a detailed clinical course as described above.

This case is the first report of a ZBTB20-JAK2 fusion defining a case of MLN-EGR presenting as B-ALL. Although remission following treatment of MLN-PJ with JAK2 inhibitors has been reported (Lierman et al. 2012; Rumi et al. 2013, 2015; Bain and Ahmad 2014; Schwaab et al. 2015; Reiter and Gotlib 2017), there is a near-complete absence of reported responses to these therapies targeting JAK mutations and/or fusion genes in B-ALLs, including Ph-like ALLs (Roberts et al. 2014; Reinert et al. 2018). This patient's case was appropriately initially classified as a B-ALL, and therapy was selected based on this diagnosis. Given the paucity of data for targeted therapy in this disease state, we chose a guidelinebased clinical approach to primary refractory B-ALL, which is largely driven by application of additional cytotoxic chemotherapy. Given her persistent MRD status after two cycles of therapy, blinatumomab, a targeted bispecific T-cell engager (BiTE) treatment was delivered as a third-line therapy based on the current labeled indication. This clinical approach ultimately led to her successful transplant and MRD-negative complete remission now at 200 $\mathrm{d}$ post-transplant. This case further highlights the need for trial-based assessments of mutation/fusion-directed agents in acute lymphoid and myeloid leukemias.

\section{METHODS}

Karyotype analysis and FISH studies using JAK2 break-apart probes (Empire Genomics) were performed and analyzed according to routine laboratory protocols. Cytoscan HD array (Thermo Fisher) was performed according to the manufacturer's instruction and analyzed using the Chromosome Analysis Suite.

B-ALL MRD status was assessed by flow cytometry, as described by the report from Children's Oncology Group study AALL0232 (Borowitz et al. 2015).

To identify the 5'-JAK2 fusion partner, the analysis was carried out using the NGS customized FusionPlex Pan-Heme kit (Archer Dx) performed at Nationwide Children's Hospital, Columbus, Ohio. This assay utilizes unidirectional primers specific for known kinase targets (GSPs) at the $3^{\prime}$ end to amplify targeted cDNA fragments that are ligated at the $5^{\prime}$ end with molecular barcodes and universal primers, enabling the identification of both known and novel fusions involving targeted genes (as listed in Supplemental Material 1). Sequencing was performed using an Illumina sequencer. The sequencing run statics are shown in Table 2. Downstream analysis identified the gene fusion using the proprietary Archer Analysis Pipeline v5.1 provided by the manufacturer. Confirmatory Sanger sequencing was performed on targeted cDNA amplicon using the following M13-tailed custom-designed primers:

Forward Primer CAGCAGACCCAGTTTGTGAC Reverse Primer ATTTTGGGAGTGTGGAGATGTGCCG

\begin{tabular}{lc}
\hline Table 2. Sequencing run statistics & \\
\hline & RNA reads (count) \\
\hline All fragments & $2,301,160$ \\
Unique fragments & $1,466,751$ \\
Unique start sites & 185,499 \\
RNA median fragment length & 187 \\
Target fusion supporting reads & 109 \\
Target fusion unique start sites & 62 \\
\hline
\end{tabular}


COLD SPRING HARBOR Molecular Case Studies
ZBTB20-JAK2 gene fusion in myeloid/lymphoid neoplasm with eosinophilia presenting as B-ALL
Competing Interest Statement

The authors have declared no competing interest.

Received November 4, 2019; accepted in revised form February 3, 2020.

\section{ADDITIONAL INFORMATION}

\section{Data Deposition and Access}

The variants reported in this study have been submitted to ClinVar (https://www.ncbi.nlm.nih .gov/clinvar/) under accession number SCV001190540.

\section{Ethics Statement}

The patient has given oral consent for the preparation and publication of this case report. The use of the clinical record and data in this report is in accordance with University of Michigan Internal Review Board Protocol (HUM00160360), which allows for retrospective analysis of deidentified data and clinical record for research purposes. The protocol HUM0016360 has been approved for a waiver of informed consent as the research involves no more than the minimal risk to the participants.

\section{Acknowledgments}

This work was supported by the Department of Pathology, Michigan Medicine, University of Michigan.

\section{Author Contributions}

W.Y.L, R.B.P., L.S., S.M.C., D.L.B., and R.J.H.R. conceptualized the study and analyzed data. W.Y.L, L.S., J.Y., H.X., E.M.P., and R.B.P. generated figures and analyzed data. W.Y.L. and L.S. drafted the manuscript. All authors reviewed and edited the manuscript.

\section{REFERENCES}

Adélaïde J, Pérot C, Gelsi-Boyer V, Pautas C, Murati A, Copie-Bergman C, Imbert M, Chaffanet M, Birnbaum D, Mozziconacci MJ. 2006. A t $(8 ; 9)$ translocation with PCM1-JAK2 fusion in a patient with T-cell lymphoma [11]. Leukemia 20: 536-537. doi:10.1038/sj.leu.2404104

Bain BJ, Ahmad S. 2014. Should myeloid and lymphoid neoplasms with PCM1-JAK2 and other rearrangements of JAK2 be recognized as specific entities? Br J Haematol 166: 809-817. doi:10.1111/bjh.12963

Borowitz MJ, Wood BL, Devidas M, Loh ML, Raetz EA, Salzer WL, Nachman JB, Carroll AJ, Heerema NA, Gastier-Foster JM, et al. 2015. Prognostic significance of minimal residual disease in high risk B-ALL: a report from Children's Oncology Group study AALL0232. Blood 126: 964-971. doi:10.1182/blood-2015-03633685

Chevrier S, Emslie D, Shi W, Kratina T, Wellard C, Karnowski A, Erikci E, Smyth GK, Chowdhury K, Tarlinton D, et al. 2014. The BTB-ZF transcription factor Zbtb20 is driven by Irf4 to promote plasma cell differentiation and longevity. J Exp Med 211: 827-840. doi:10.1084/jem.20131831

Ehrentraut S, Nagel S, Scherr ME, Schneider B, Quentmeier H, Geffers R, Kaufmann M, Meyer C, ProchorecSobieszek M, Ketterling RP, et al. 2013. t(8;9)(p22;p24)/PCM1-JAK2 activates SOCS2 and SOCS3 via STAT5. PLoS One 8: e53767. doi:10.1371/journal.pone.0053767

Lierman E, Selleslag D, Smits S, Billiet J, Vandenberghe P. 2012. Ruxolitinib inhibits transforming JAK2 fusion proteins in vitro and induces complete cytogenetic remission in $\mathrm{t}(8 ; 9)(\mathrm{p} 22 ; \mathrm{p} 24) / P C M 1-J A K 2$-positive chronic eosinophilic leukemia. Blood 120: 1529-1531. doi:10.1182/blood-2012-06-433821

Maeda T. 2016. Regulation of hematopoietic development by ZBTB transcription factors. Int J Hematol 104: 310-323. doi:10.1007/s12185-016-2035-x

Meeker TC, Hardy D, Willman C, Hogan T, Abrams J. 1990. Activation of the interleukin-3 gene by chromosome translocation in acute lymphocytic leukemia with eosinophilia. Blood 76: 285-289. doi:10.1182/ blood.V76.2.285.285

Mullighan CG, Miller CB, Radtke I, Phillips LA, Dalton J, Ma J, White D, Hughes TP, Le Beau MM, Pui C, et al. 2008. BCR-ABL1 lymphoblastic leukaemia is characterized by the deletion of Ikaros. Nature 453: 110-114. doi:10.1038/nature06866

Patterer V, Schnittger S, Kern W, Haferlach T, Haferlach C. 2013. Hematologic malignancies with PCM1-JAK2 gene fusion share characteristics with myeloid and lymphoid neoplasms with eosinophilia and abnormalities of PDGFRA, PDGFRB, and FGFR1. Ann Hematol 92: 759-769. doi:10.1007/s00277-013-1695-3 
C OLD SPRING HARBOR Molecular Case Studies
ZBTB20-JAK2 gene fusion in myeloid/lymphoid neoplasm with eosinophilia presenting as B-ALL

Peterson JF, Blackburn PR, Webley MR, Pearce KE, Williamson CM, Vasmatzis G, Smadbeck JB, Bieliauskas SL, Reichard KK, Ketterling RP, et al. 2019. Identification of a novel ZBTB20-JAK2 fusion by mate-pair sequencing in a young adult with B-lymphoblastic leukemia/lymphoma. Mayo Clin Proc 94: 1381-1384. doi:10 .1016/j.mayocp.2019.04.030

Reinert RB, Bixby D, Koenig RJ. 2018. Fibroblast growth factor 23-induced hypophosphatemia in acute leukemia. J Endocr Soc 2: 437-443. doi:10.1210/js.2018-00010

Reiter A, Gotlib J. 2017. Myeloid neoplasms with eosinophilia. Blood 129: 704-714. doi:10.1182/blood-201610-695973

Reiter A, Walz C, Watmore A, Schoch C, Blau I, Schlegelberger B, Berger U, Telford N, Aruliah S, Yin JA, et al. 2005. The $t(8 ; 9)(p 22 ; p 24)$ is a recurrent abnormality in chronic and acute leukemia that fuses PCM1 to JAK2. Cancer Res 65: 2662-2667. doi:10.1158/0008-5472.CAN-04-4263

Roberts KG, Li Y, Payne-Turner D, Harvey RC, Yang Y-L, Pei D, McCastlain K, Ding L, Lu C, Song G, et al. 2014. Targetable kinase-activating lesions in Ph-like acute lymphoblastic leukemia. N Engl J Med 371: 10051015. doi:10.1056/NEJMoa1403088

Roberts KG, Gu Z, Payne-Turner D, McCastlain K, Harvey RC, Chen IM, Pei D, lacobucci I, Valentine M, Pounds SB, et al. 2017. High frequency and poor outcome of Philadelphia chromosome-like acute lymphoblastic leukemia in adults. J Clin Oncol 35: 394-401. doi:10.1200/JCO.2016.69.0073

Rumi E, Milosevic JD, Casetti I, Dambruoso I, Pietra D, Boveri E, Boni M, Bernasconi P, Passamonti F, Kralovics $\mathrm{R}$, et al. 2013. Efficacy of ruxolitinib in chronic eosinophilic leukemia associated with a PCM1-JAK2 fusion gene. J Clin Oncol 31: e269-e271. doi:10.1200/JCO.2012.46.4370

Rumi E, Milosevic JD, Selleslag D, Casetti I, Lierman E, Pietra D, Cavalloni C, Bellini M, Milanesi C, Dambruoso I, et al. 2015. Efficacy of ruxolitinib in myeloid neoplasms with PCM1-JAK2 fusion gene. Ann Hematol 94: 1927-1928. doi:10.1007/s00277-015-2451-7

Schwaab J, Knut M, Haferlach C, Metzgeroth G, Horny HP, Chase A, Tapper W, Score J, Waghorn K, Naumann $\mathrm{N}$, et al. 2015. Limited duration of complete remission on ruxolitinib in myeloid neoplasms with PCM1JAK2 and BCR-JAK2 fusion genes. Ann Hematol 94: 233-238. doi:10.1007/s00277-014-2221-y

Swerdlow SH, Campo E, Harris NL, Jaffe ES, Pileri SA, Stein H TJ. 2017. WHO classification of tumours of haematopoietic and lymphoid tissues, revised 4th ed. International Agency for Research on Cancer, Lyon.

Tang G, Sydney Sir Philip JK, Weinberg O, Tam W, Sadigh S, Lake JI, Margolskee EM, Rogers HJ, Miranda RN, Bueso-Ramos CC, et al. 2018. Hematopoietic neoplasms with 9p24/JAK2 rearrangement: a multicenter study. Mod Pathol 32: 490-498. doi:10.1038/s41379-018-0165-9

Tasian SK, Loh ML, Hunger SP. 2017. Philadelphia chromosome-like acute lymphoblastic leukemia. Blood 130: 2064-2072. doi:10.1182/blood-2017-06-743252

van $\operatorname{der}$ Veer A, Waanders E, Pieters R, Willemse ME, Van Reijmersdal S V, Russell LJ, Harrison CJ, Evans WE, van der Velden VHJ, Hoogerbrugge PM, et al. 2013. Independent prognostic value of BCR-ABL1-like signature and IKZF1 deletion, but not high CRLF2 expression, in children with B-cell precursor ALL. Blood 122: 2622-2629. doi:10.1182/blood-2012-10-462358

Wang Y, Bhattacharya D. 2014. Adjuvant-specific regulation of long-term antibody responses by ZBTB20. J Exp Med 211: 841-856. doi:10.1084/jem.20131821

Zhu C, Chen G, Zhao Y, Gao XM, Wang J. 2018. Regulation of the development and function of B cells by ZBTB transcription factors. Front Immunol 9: 580. doi:10.3389/fimmu.2018.00580 


\section{COLD SPRING HARBOR Molecular Case Studies}

\section{The diagnostic challenges and clinical course of a myeloid/lymphoid neoplasm with eosinophilia and ZBTB20-JAK2 gene fusion presenting as B-lymphoblastic leukemia}

Winston Y. Lee, Ruthann B. Pfau, Sarah M. Choi, et al.

Cold Spring Harb Mol Case Stud 2020, 6: a004937

Access the most recent version at doi: $10.1101 / \mathrm{mcs} . a 004937$
Supplementary http://molecularcasestudies.cshlp.org/content/suppl/2020/03/31/mcs.a004937.D Material C1
References This article cites 24 articles, 10 of which can be accessed free at: http://molecularcasestudies.cshlp.org/content/6/2/a004937.full.html\#ref-list-1
License This article is distributed under the terms of the Creative Commons Attribution-NonCommercial License, which permits reuse and redistribution, except for commercial purposes, provided that the original author and source are credited.
Email Alerting Receive free email alerts when new articles cite this article - sign up in the box at the Service top right corner of the article or click here.

